\title{
Behaviors of end milling Inconel 718 superalloy by cemented carbide tools
}

\author{
Y.S. Liao ${ }^{a, *}$, H.M. Lin $^{b}$, J.H. Wang ${ }^{a}$ \\ a Department of Mechanical Engineering, National Taiwan University, Taipei 106, Taiwan \\ b Department of Mechanical Engineering, Nan Kai Institute of Technology, Nantou 542, Taiwan
}

\section{A R T I C L E I N F O}

\section{Keywords:}

Inconel 718

High speed cutting

Carbide tools

End milling

\begin{abstract}
A B S T R A C T
End milling of Inconel 718 under various cutting speeds by cemented carbide tools was conducted. For slot milling, it is found that the increase of cutting temperature and strain hardening are responsible for the difficulty at low speed cutting. Tool failure is mainly in the form of chipping and breakage of the cutting edge. At medium cutting speeds, softening of work material due to special thermal stability property of $\gamma^{\prime}$ precipitation of Inconel 718 leads to a reduction of cutting force, and tool life is improved with the increase of speed. But when cutting speed is further increased, most of the chips are welded on both sides of the slot, and chip flow is retarded. The cutting temperature would rise drastically and plastic deformation of cutting tool takes place eventually. Cutting speed plays a less important role in side milling since chips can flow more smoothly. Based on this study, it is found that high cutting temperature and difficult chip disposal are two main problems encountered in highspeed end milling of Inconel 718. It is also concluded that there exists an appropriate range of cutting speed in end milling of Inconel 718 by cemented carbide tools. On the contrary, feed does not have a significant effect for both kinds of milling operations.
\end{abstract}

(c) 2007 Elsevier B.V. All rights reserved.

\section{Introduction}

Inconel 718 superalloy has been applied widely in high temperature, high load and corrosion resistant environments due to its superior properties. However, Inconel 718 is a wellknown difficult-to-cut material. Its small thermal conductivity and volume specific heat result in high cutting temperature. Good mechanical properties together with its severe work hardening tendency lead to high cutting force. In addition, chips are easy to weld on the tool to form build up edge (BUE). As a result, cutting tool wears rapidly during machining.

Several studies on the machining of nickel base alloys had disclosed tool wear mechanisms, for example (Liao and Shiue, 1996; Jawaid et al., 2000; Deng et al., 2005). Also, the use of different tool materials such as aluminum oxide base cermet, special coating of carbide, whisker-reinforced ceramic, CBN, etc. to cut this kind of material had been investigated (Narutaki and Yamane, 1993; Gatto and Iuliano, 1997; Choudhury and El-Baradie, 1998; Ezugwu et al., 1999). However, machining of Inconel 718 remained a difficult problem. An effective approach is still not available.

In recent years, high speed machining (HSM) technology is becoming matured owing to the advance of machine tool and control system. A higher metal removal rate is not the only advantage of HSM. It has the features of lower cutting force, improvement of the surface quality, no critical heat of the workpiece, etc. According to the study by the PTW (Institute for Production Engineering and Cutting Machine Tools) in Darmstadt/Germany, reduction of more than $50 \%$ cutting time and $30 \%$ cutting cost can be achieved (Schulz, 1992). The use

\footnotetext{
* Corresponding author. Tel.: +886 22362 6431; fax: +886 223631755 .

E-mail address: liaoys@ntu.edu.tw (Y.S. Liao). 

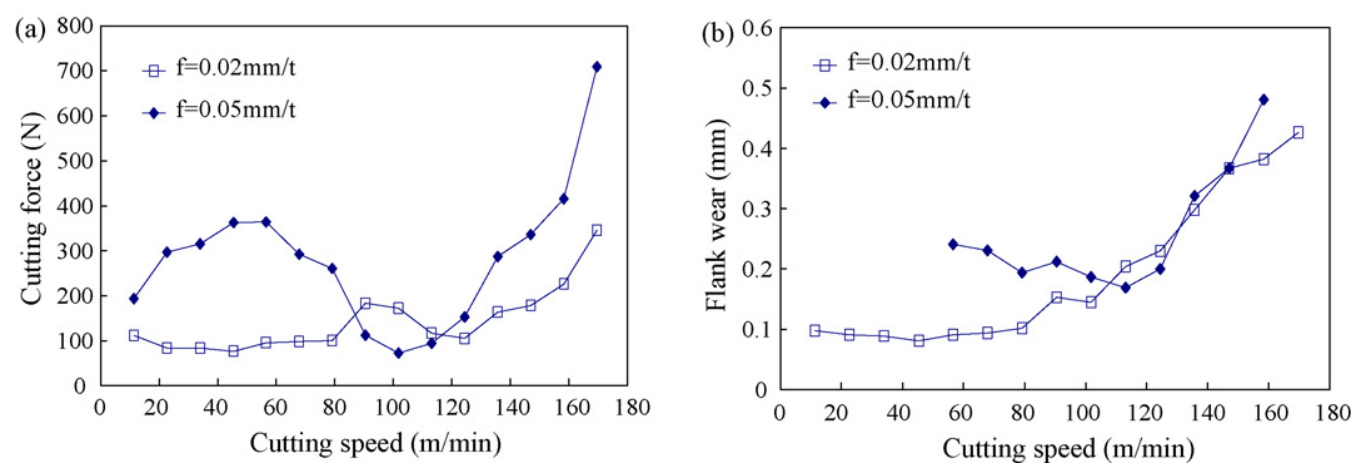

Fig. 1 - Variations of (a) cutting force and (b) flank wear with speed for slot milling.

of HSM for the aluminum alloys of aircraft parts has long been recognized. Machining of die steels by HSM is another appealing example. It has been successfully applied to die and mold manufacturing industry in recent years. Results show that it is competitive to electrical discharge machining in certain aspects. HSM has been reported to be appropriate for machining nickel-based alloys as well (Schulz, 1992; Choudhury and El-Baradie, 1998; Li et al., 2002). Several studies conducted in this area are described below.

In high speed turning of Inconel 718, Kitagawa et al. (1997) investigated the wear characteristics of two different ceramic tools; it was observed that the wear resistance of TiC added alumina ceramic was superior to that of silicon nitride within the speed range from 250 to $500 \mathrm{~m} / \mathrm{min}$. A severe notch was generated on the cutting edge in the vicinity of depth of cut. It was suggested that the side flow of the chip and burrs on the workpiece were responsible for the formation of serious notch wear. Jindal et al. (1999) found that TiAlN coated carbide tools performed better than TiN and TiCN coated tools. The work of Li et al. (2002) and Dudzinski et al. (2004) also showed that PVD TiAlN coated carbides were suitable for turning Inconel 718 up to a cutting speed of $100 \mathrm{~m} / \mathrm{min}$. Regarding tool geometry, it was found by El-Wardany et al. (1996) that an increase of side cutting edge angle would lead to a lower heat generation and the improvement of tool performance.

With respect to the high speed milling investigation, experiments were carried out by Sharman et al. (2001) to assess the performance of TiAlN and CrN coated carbide tools at the cutting speed of 90 and $150 \mathrm{~m} / \mathrm{min}$ for ball end milling. The longest tool life was obtained with TiAlN coated tools at $90 \mathrm{~m} / \mathrm{min}$. This demonstrated that the choice of tool coating was the main factor to affect tool life. The reason why TiAlN coated tools performed better than $\mathrm{CrN}$ coated tools was due to the higher hardness and oxidation resistance of TiAlN coating.

All these studies provide more insight of tool performance in high speed cutting of Inconel 718. However, the published works are mainly focused on the effect of tool materials, coating materials, tool geometries or cutting parameters on the performance of cutting tool. The correlation between cutting performance and the variations of mechanical properties of work materials during machining has rarely been studied. The purpose of this paper is to study more comprehensively the cutting behaviors of end milling of Inconel 718 with carbide (a)

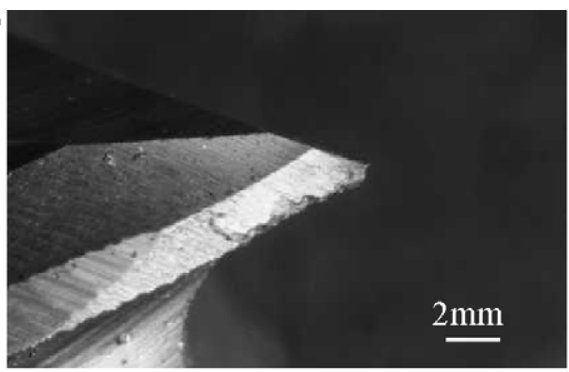

(c)

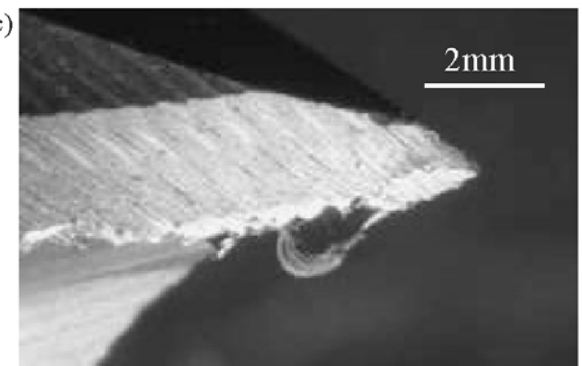

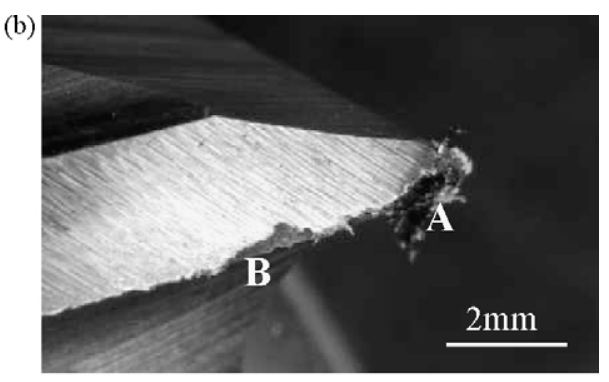

(d)

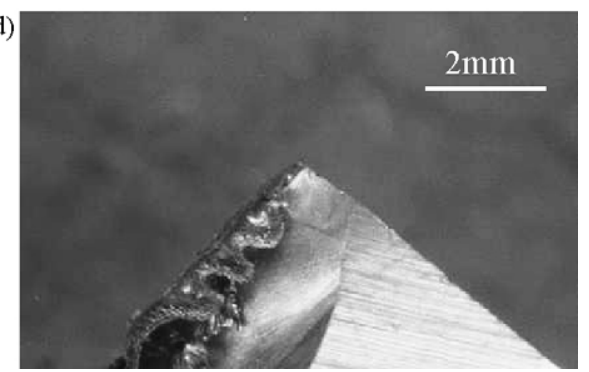

Fig. 2 - Tool conditions for slot milling (a) $V=22.6 \mathrm{~m} / \mathrm{min}, f=0.05 \mathrm{~mm} /$ tooth; (b) $V=56.6 \mathrm{~m} / \mathrm{min}, f=0.05 \mathrm{~mm} /$ tooth; (c) $V=113.1 \mathrm{~m} / \mathrm{min}, f=0.05 \mathrm{~mm} /$ tooth; (d) $V=147.0 \mathrm{~m} / \mathrm{min}, f=0.05 \mathrm{~mm} /$ tooth. 


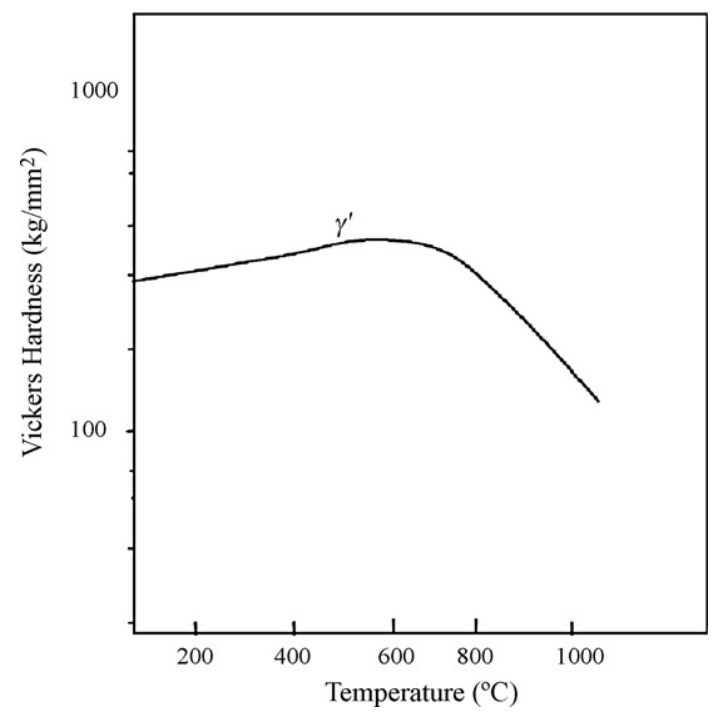

Fig. 3 - Thermal stability diagram of $\gamma^{\prime}$ precipitation.

tool. In particular the characteristics at high cutting speed, take into account the change of its hardness during cutting.

\section{Experiments}

It was reported that ceramic and CBN tools could be applied for high speed turning of nickel base superalloys (Narutaki and Yamane, 1993; Li et al., 2002; Deng et al., 2005). Nevertheless, they are quite expensive. Besides, the use of ceramic results in serious notch, and there is diffusion problem in high speed cutting of nickel base alloys by CBN tool material. Hence, in our experiments, end milling cutter of $\mathrm{K} 10$ carbide was used. Tool wear/failure was observed under a toolmaker's microscope. The cutting force was measured by a Kistler type 9257BA dynamometer. A vertical high-speed machining center (Vector65/I) was used for the experiments. Adjustment of rotational speed was accomplished through an inverter, and its highest speed was $24000 \mathrm{rpm}$. The milling cutter having diameter of $12 \mathrm{~mm}$ and helix angle of $45^{\circ}$ was used. Both slot milling and side milling were conducted. For slot milling the depth of cut was $0.5 \mathrm{~mm}$, cutting length was $50 \mathrm{~mm}$, and feeds were $0.02 \mathrm{~mm} /$ tooth, and $0.05 \mathrm{~mm} /$ tooth, respectively. For side milling, depth of immersion was $12 \mathrm{~mm}$, and depth of cut (cut width) was $1.0 \mathrm{~mm}$. Cutting length and feed were the same as slot milling.

\section{Results and discussion}

Results of slot milling and side milling are presented separately.

\subsection{Slot milling}

Variations of cutting force and flank wear with cutting speed are shown in Fig. 1. It can be seen from Fig. 1(a) that cutting force for the feed of $0.05 \mathrm{~mm} /$ tooth is increased with cutting speed gradually until $56.6 \mathrm{~m} / \mathrm{min}$ (corresponding to spindle (a)

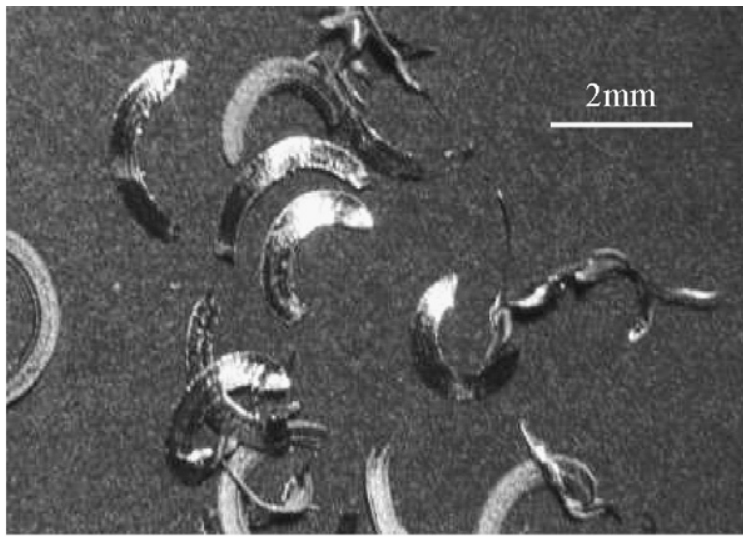

(b)

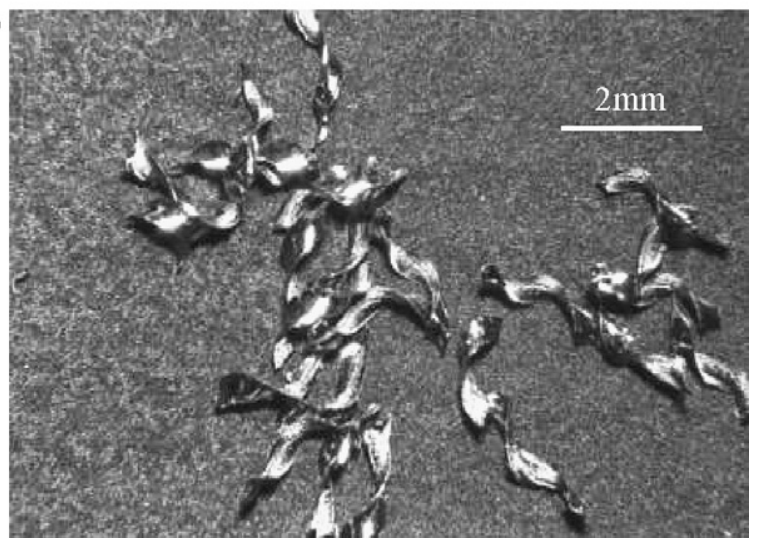

Fig. 4 - chips for slot milling (a) $V=22.6 \mathrm{~m} / \mathrm{min}$, $f=0.05 \mathrm{~mm} /$ tooth; (b) $\mathrm{V}=90.5 \mathrm{~m} / \mathrm{min}, f=0.05 \mathrm{~mm} /$ tooth.

speed of $1500 \mathrm{rpm})$. Then, it starts to decrease slowly. It reaches minimum cutting force $(72.7 \mathrm{~N})$ at the speed of $101.8 \mathrm{~m} / \mathrm{min}$. From then on, it increases with speed. Quite different behavior is found for the feed of $0.02 \mathrm{~mm} /$ tooth. There is no apparent variation of cutting force when it is cut at speed below $90.5 \mathrm{~m} / \mathrm{min}$. Its value remains at about $100 \mathrm{~N}$. Cutting force increases monotonically after the speed of $124.4 \mathrm{~m} / \mathrm{min}$. The reason why cutting force has this kind of behavior will be discussed later.

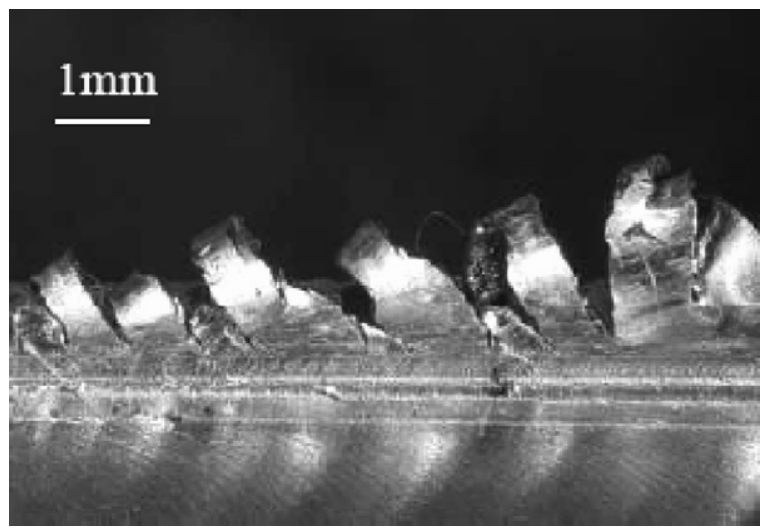

Fig. 5 - Welded chips on the sides of the slot for slot milling at $V=124.4 \mathrm{~m} / \mathrm{min}, f=0.05 \mathrm{~mm} /$ tooth. 


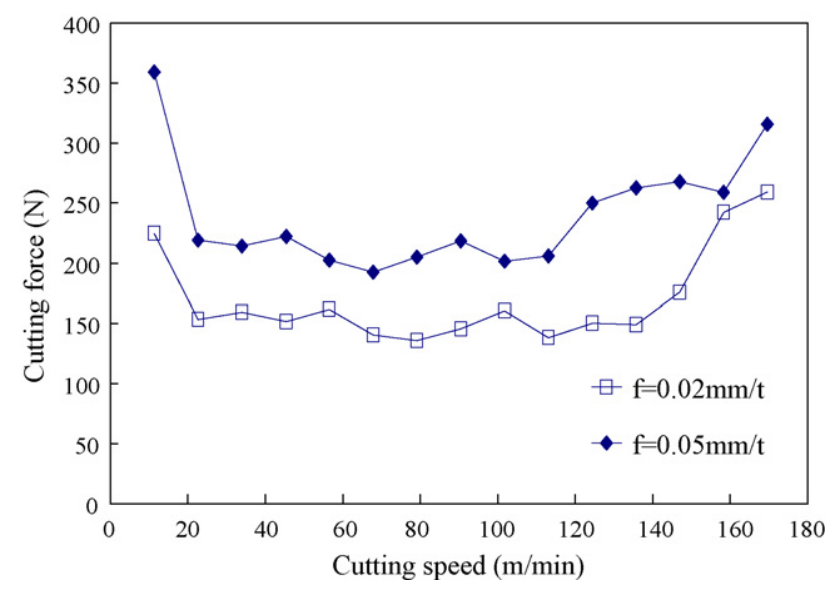

Fig. 6 - Variation of cutting force with speed for side milling.

Tool condition for low speed cutting $(\mathrm{V}=22.6 \mathrm{~m} / \mathrm{min})$ at a feed of $0.05 \mathrm{~mm} /$ tooth is shown in Fig. 2(a). Failure is mainly breakage of cutting edge. When the speed is increased to $56.6 \mathrm{~m} / \mathrm{min}$, breakage of cutting edge becomes even more serious (Fig. 2(b)). The tip of the peripheral cutting edge is burned to black color; there is BUE, and irregular chipping (part A) and breakage (part $B$ ) of the cutting edge. This condition corresponds to the maximum cutting force in Fig. 1(a). Beyond the speed of $56.6 \mathrm{~m} / \mathrm{min}$, flank wear dominates tool wear. Tool face remains relatively smooth. When the speed is at $113.1 \mathrm{~m} / \mathrm{min}$, chip starts to weld on the cutting edge (Fig. 2(c)). The amount of chip welded on the cutting edge increases with cutting speed, which leads to the dramatic increase of cutting force. At speed of $147.0 \mathrm{~m} / \mathrm{min}$, chips are welded even onto the flute (Fig. 2(d)). Tools wear for the feed of $0.02 \mathrm{~mm} /$ tooth is very similar.

Kear et al. (1970) had pointed out that there is large amount of $\gamma^{\prime}$ and $\gamma^{\prime \prime}$ precipitates when Inconel 718 alloy is deformed. This leads to difficult movement of dislocations, and it is the main reason of work hardening. Sim and Hagel (1972) found that $\gamma^{\prime}$ precipitates integrated satisfactorily with matrix at high temperature $\left(650^{\circ} \mathrm{C}\right)$ and causes high flow stress (Fig. 3). Below $650^{\circ} \mathrm{C}$, hardness is increased with temperature. In other words, workpiece becomes harder and harder with the increase of cutting temperature. Evidently, workpiece hardness is increased with cutting speed. This is because cutting temperature is increased with cutting speed when feed is kept constant. The increase of workpiece hardness also causes cutting temperature to increase. These double effects together with severe breakage of cutting tool (Fig. 2(b)) cause cutting temperature to increase drastically. As a result, cutting force is increased with cutting speed. When temperature is higher than $650^{\circ} \mathrm{C}$, hardness of $\gamma^{\prime}$ reduces rapidly. Hence cutting force is decreased accordingly. The change from segmented chip (Fig. 4(a)) under low speed cutting to longer chip similar to the case of continuous cutting (Fig. 4(b)) at high cutting speed confirms previous explanation.

However, such a good cutting condition cannot be maintained when cutting speed is further increased. The high cutting temperature owing to high cutting speed would soften workpiece. But at the same time cutting tool is softened if cutting temperature is higher than $1100^{\circ} \mathrm{C}$, the hot hardness of carbide. Once cutting tool cannot withstand the cutting force, its cutting action becomes that of extrusion (similar to rubbing in grinding). As shown in Fig. 5 when it is cut at $124.4 \mathrm{~m} / \mathrm{min}$, there is only a small amount of chip flows out of the cutting zone. Most of the chips are pushed to the sides of the slot, and they are piece-wisely stacked. The chips welded on both sides of the slot retarding chip flow, and cutting temperature will increase because the heat generated cannot be dissipated with the chips. At this moment, the cutting force will increase rapidly. The same tool material but a helix angle of $30^{\circ}$ has been tested. Very different results from the above mentioned results are observed. Cutting tool becomes red even at $90.5 \mathrm{~m} / \mathrm{min}$ for the feed of $0.05 \mathrm{~mm} /$ tooth. All chips are welded onto the sides of the slot, and there is no chip disposal. Cutting force is over $600 \mathrm{~N}$. This indicates that easy chip disposal (i.e. use of high helix angle tool) is very important in high-speed slot milling of Inconel 718.

In comparison with the cutting force for the feed of $0.05 \mathrm{~mm} /$ tooth, the hunch portion for the feed of $0.02 \mathrm{~mm} /$ tooth in Fig. 1(a) is less significant. This may be caused by the lower cutting force resulted from the smaller metal removal rate and in turns the rate of temperature rise is decreased. Hence the strain hardening can be reduced to a lower extent. If $\bar{\theta}_{\mathrm{T}}$ denotes the mean cutting temperature, then for carbide tools, $\bar{\theta}_{\mathrm{T}}$ is related to cutting speed and feed by (Kalpakjian, 2001)

$\bar{\theta}_{\mathrm{T}} \propto \mathrm{V}^{0.2} f^{0.125}$

Based on this expression, the top of hunch portion of the cutting force for the feed of $0.02 \mathrm{~mm} /$ tooth in Fig. 1(a) locates somewhat between 90.5 and $101.8 \mathrm{~m} / \mathrm{min}$. If the transient temperature of $\gamma^{\prime}\left(650^{\circ} \mathrm{C}\right)$ is the same, the cutting speed will be in between 51.0 and $57.4 \mathrm{~m} / \mathrm{min}$ for the feed of $0.05 \mathrm{~mm} / \mathrm{tooth}$. This range is exactly the top of hunch portion for the feed of (a)

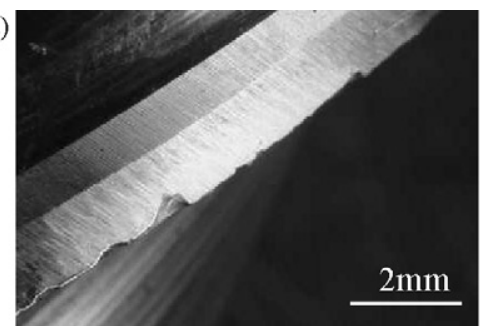

(b)

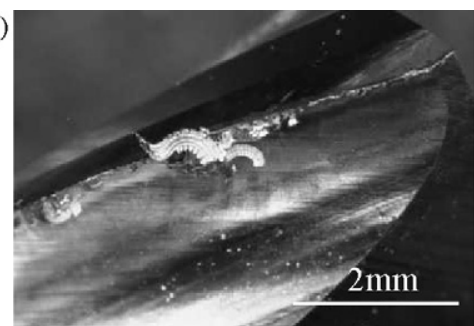

(c)

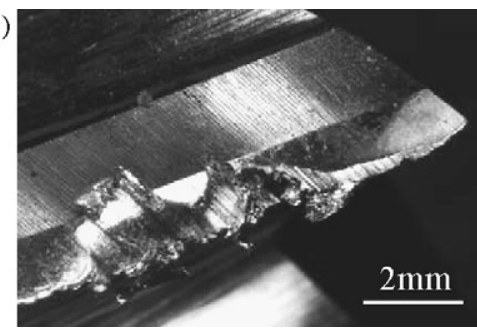

Fig. 7 - Tool conditions for side milling (a) $V=11.3 \mathrm{~m} / \mathrm{min}, f=0.05 \mathrm{~mm} /$ tooth; (b) $V=135.7 \mathrm{~m} / \mathrm{min}, f=0.05 \mathrm{~mm} /$ tooth; (c) $V=169.7 \mathrm{~m} / \mathrm{min}, f=0.05 \mathrm{~mm} /$ tooth. 
(a)

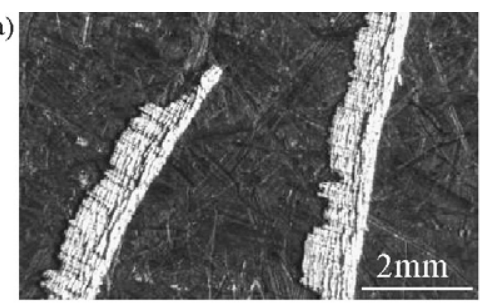

(d)

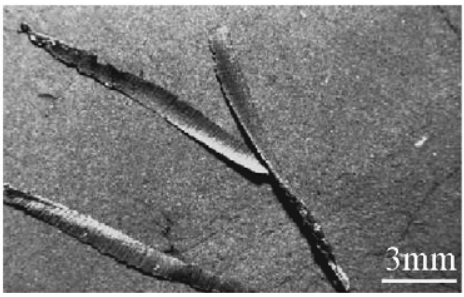

(b)

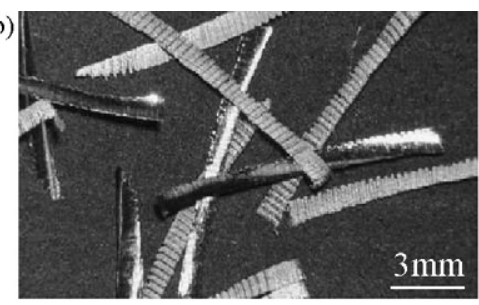

(e)

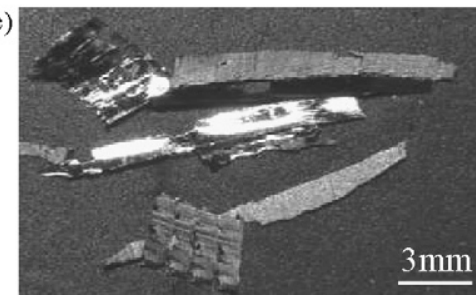

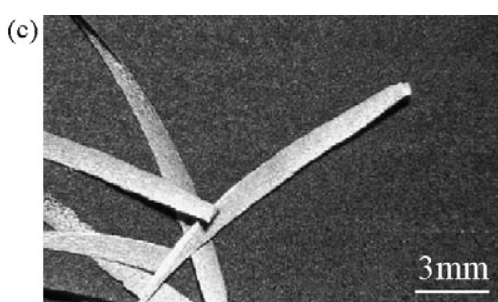

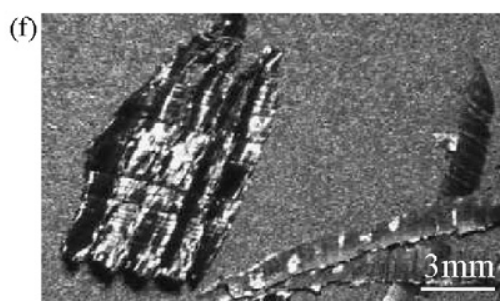

Fig. 8 - Chips for side milling (a)V=33.9 m/min, $f=0.05 \mathrm{~mm} /$ tooth; (b) $\mathrm{V}=56.6 \mathrm{~m} / \mathrm{min}, f=0.05 \mathrm{~mm} /$ tooth; (c) V=101.8 $\mathrm{m} / \mathrm{min}$, $f=0.05 \mathrm{~mm} /$ tooth; (d) V= $135.7 \mathrm{~m} / \mathrm{min}, f=0.05 \mathrm{~mm} /$ tooth;(e) $\mathrm{V}=147.0 \mathrm{~m} / \mathrm{min}, f=0.05 \mathrm{~mm} /$ tooth; (f) $\mathrm{V}=169.7 \mathrm{~m} / \mathrm{min}$, $f=0.05 \mathrm{~mm} /$ tooth.

$0.05 \mathrm{~m} /$ tooth as shown in the figure. Hence the variation of cutting force with speed is similar under different feed conditions.

According to previous discussions, it is concluded that cutting temperature and chip disposal are two very important and correlated factors affecting slot milling of Inconel 718. Cutting temperature is related to cutting speed. When speed is too low $(\mathrm{V}<56.6 \mathrm{~m} / \mathrm{min})$, cutting temperature will be lower than the softening point of $\gamma^{\prime}$. Within this speed range the higher the cutting speed, the severer is the strain hardening of the work material, and it is detrimental to cutting. When cutting speed is too high $(\mathrm{V}>124.4 \mathrm{~m} / \mathrm{min})$, work material is softened but cutting temperature will be too high for the cutting tool to withstand as well. Under this condition, welding of the chips on the work surface becomes very serious, and it is more inappropriate for cutting. Hence, it is essential to maintain cutting speed within the range of $90-110 \mathrm{~m} / \mathrm{min}$ so that softening of work material occurs on one hand. On the other hand, carbide tool can still retain its cutting ability.

\subsection{Side milling}

Variation of cutting force with cutting speed is shown in Fig. 6. It is concave upward for both feeds. Cutting force is large for the speed of $11.3 \mathrm{~m} / \mathrm{min}$ since the tool is subjected to a very large impact force at the instant it contacts the workpiece at very low cutting speed. It then drops to a stable state at the speed range of $22.6-113.1 \mathrm{~m} / \mathrm{min}$ for the feed of $0.05 \mathrm{~mm} /$ tooth, and $22.6-135.7 \mathrm{~m} / \mathrm{min}$ for the feed of $0.02 \mathrm{~mm} /$ tooth. After this speed, cutting force starts to rise gradually.

Cutting tool's conditions with respect to speed are very similar to those of slot milling. There is very small amount of flank wear at low cutting speeds. Breakage and chipping dominate tool failure (Fig. 7(a)). Chips welded on the cutting edge are found apparently until the speed of $135.7 \mathrm{~m} / \mathrm{min}$ (Fig. 7(b)), in comparison with $113.1 \mathrm{~m} / \mathrm{min}$ of slot milling (Fig. 2(c)). When the cutting speed is further increased, the welding of chips becomes even more serious. Fig. 7(c) shows the tool and the chips when cutting is conducted at $169.7 \mathrm{~m} / \mathrm{min}$. It can be seen that cutting edge of the front part is seriously worn, and chips are welded even onto the secondary flank.

The chips formed at different cutting speeds are shown in Fig. 8. At very low speed, the chip is relatively disintegrated (Fig. 8(a)). It becomes more or less integrated and the trace of shear deformation can be clearly seen when the speed is increased to $56.6 \mathrm{~m} / \mathrm{min}$ as displayed in Fig. 8(b). The chip becomes very smooth and shinny at the speed of $101.8 \mathrm{~m} / \mathrm{min}$ (Fig. 8(c)). Essentially there is not much variation of chip type for the speed in the range of $33.9-101.8 \mathrm{~m} / \mathrm{min}$. Within this range cutting force is quite stable (referring to Fig. 6). But when the speed is higher than $135.7 \mathrm{~m} / \mathrm{min}$, the chip produced becomes relatively disintegrated again (Fig. 8(d)). Chips start to weld together at the speed of $147.0 \mathrm{~m} / \mathrm{min}$ (Fig. 8(e)). This indicates that cutting temperature is changing. As shown in Fig. 8(f) where speed is even higher $(\mathrm{V}=169.7 \mathrm{~m} / \mathrm{min})$, welding of chips is more obvious. All the chips are burned to yellow color. Hence, the increase of cutting force for the speed higher than $135.7 \mathrm{~m} / \mathrm{min}$ is attributed to the more difficult disposal of chips resulted from the increase of cutting temperature.

Comparing with slot milling, chip flow is easier and cutting force per unit length of cutting edge is much smaller for side milling. As a result, the change of temperature with speed is less significant and there is no apparent hunch phenomenon in cutting force. Hence the speed range for stable cutting is wider $(55-135 \mathrm{~m} / \mathrm{min})$.

\section{Conclusion}

Based on this study, the following conclusions can be drawn:

(1) It is detrimental to high-speed slot milling of Inconel 718 alloys when cutting temperature is lower than $\gamma^{\prime}$ softening temperature. Below this critical temperature, work material is easier to strain hardening with the increase of temperature. On the contrary, it is beneficial if cutting temperature is higher than this critical temperature. But when the temperature is higher than the hardness of cut- 
ting tools, it is even worse for cutting. In other words, cutting temperature plays a very important role in cutting of Inconel 718 alloys.

(2) Chip is very difficult to be disposed in high-speed slot milling of Inconel 718 alloys, and temperature is easy to rise as a result. Since, cutting temperature is related to cutting speed, proper selection of cutting speed is essential. In our experiments, cutting speed of $90-110 \mathrm{~m} / \mathrm{min}$ is appropriate for slot milling, and $55-135 \mathrm{~m} / \mathrm{min}$ is appropriate of side milling.

(3) Cutting speed is related closely to cutting force and tool wear/failure in slot milling of Inconel 718 alloys. The effect of feed is relatively insignificant.

(4) Cutting temperature and chip flow condition are two most important factors affecting high speed milling of Inconel 718 alloys while strength of cutting edge is not the pertinent factor.

\section{REFERENCES}

Choudhury, I.A., El-Baradie, M.A., 1998. Machining nickel base superalloys: Inconel 718. Proc. IMechE B: J. Eng. Manuf. 212, 195-206.

Deng, J., Liu, L., Liu, J., Zhao, J., Yang, X., 2005. Failure mechanisms of TiB2 particle and $\mathrm{SiC}$ whisker reinforced $\mathrm{Al} 2 \mathrm{O} 3$ ceramic cutting tools when machining nickel-based alloys. Int. J. Mach. Tools Manufact. 45 (12-13), 1393-1401.

Dudzinski, D., Devillez, A., Moufki, A., Larrouquere, D., Zerrouki, V., Vigneau, J., 2004. A review of developments towards dry and high speed machining of Inconel 718 alloy. Int. J. Mach. Tools Manufact. 44 (4), 439-456.

El-Wardany, T.I., Mohammed, E., Elbestawi, M.A., 1996. Cutting temperature of ceramic tools in high speed machining of difficult-to-cut materials. Int. J. Mach. Tools Manufact. 36 (5), 611-634.

Ezugwu, E.O., Wang, Z.M., Okeke, C.I., 1999. Tool life and surface integrity when machining Inconel 718 with PVD- and CVD-coated tools. Tribol. Trans. 42 (2), 353-360.

Gatto, A., Iuliano, L., 1997. Advanced coated ceramic tools for machining superalloys. Int. J. Mach. Tools Manufact. 37 (5), 591-605.

Jawaid, A., Koksal, S., Sharif, S., 2000. Wear behavior of PVD and CVD coated carbide tools when face milling Inconel 718. Tribol. Trans. 43 (2), 325-331.

Jindal, P.C., Santhanam, A.T., Schleinkofer, U., Shuster, A.F., 1999. Performance of PVD TiN, TiCN and TiAlN coated cemented carbide tools in turning. Int. J. Refract. Met. Hard Mater. 17, 163-170.

Kalpakjian, S., 2001. Manufacturing Engineering and Technology, 4th ed. Prentice-Hall Inc.

Kear, B.H., Oblak, J.M., Giami, A.F., 1970. Stacking faults in gamma prime precipitation hardened nickel-bse alloys. Metal. Tran. 1, 2477-2486.

Kitagawa, T., Kubo, A., Maekawa, K., 1997. Temperature and wear of cutting tools in high speed machining of Inconel 718 and Ti-6Al-2Sn. Wear 202, 142-148.

Li, L., He, N., Wang, M., Wang, Z.G., 2002. High speed cutting of Inconel 718 with coated carbide and ceramic inserts. J. Mater. Process. Technol 129 (1-3), 127-130.

Liao, Y.S., Shiue, R.H., 1996. Carbide tool wear mechanism in turning of Inconel 718 superalloy. Wear 193, 16-24.

Narutaki, N., Yamane, Y., 1993. High-speed machining of Inconel 718 with ceramic tools. Ann. CIRP 42 (1), 103-106.

Schulz, H., 1992. High speed machining. Ann. CIRP 41 (2), 637643.

Sharman, A., Dewes, R.C., Aspinwall, D.K., 2001. Tool life when high speed ball nose end milling Inconel 718. J. Mater. Process. Technol 118 (1-3), 29-35.

Sim, C.T., Hagel, W.C., 1972. The Superalloys. General Electric Company. 